\title{
Aselsan Academy: A New Industry-Academia Partnership Model
}

\section{Prof. Mehmet Çelik, Aselsan Inc., Council of Higher Education of Turkey}

Mehmet Çelik graduated from Middle East Technical University (Turkey), Department of Mechanical Engineering in 1989. He obtained his M.Sc. and PhD degrees in the same department in 1991 and 1997, respectively. During that time, he had worked as a teaching assistant. In 1995-1996, he had studied as a research scientist at Ohio State University. Between 1998-2010, he had worked in ASELSAN MST/REHIS as Mechanical Analysis Manager, Test Unit Manager and Senior Lead Design Engineer. In 2010, he was appointed as a full-time professor at KTO Karatay University. He served as the Head of the Department of Mechatronics and Mechanical Engineering Department, Vice Dean and Director of the Institute of Science at this university. Then, he had worked as a Vice President of TUBITAK (Scientific and Technological Research Council of Turkey) between 2015 and 2017. He has become a member of TÜBA (Turkish Academy of Sciences). He was appointed as the Vice President of ASELSAN-Defence Industry, responsible from Technology and Strategy Management, in 2017. In 2018, he was appointed as a Higher Education Council Board Member and currently serves as the head of University-Industry Cooperation Committee. Recently, he has been appointed as a member of the Science, Technology and Innovative Technology Policies Committee of the Presidency. 
ASELSAN ACADEMY: A NEW MODEL IN INDUSTRY-ACADEMIA PARTNERSHIP 


\section{Introduction}

From the past to the present, technological and economic development has been strongly linked with productive industry-academia partnership (IAP) [1]. Countries have tried to develop methods that suits well to their own resources, geography, culture and principles and then improve them in time.

In this paper, Aselsan Academy, formed by Aselsan Inc. and four major Turkish research universities is introduced. Firstly, employed model for Aselsan Academy is presented, including its aims, functioning and structure after a brief historical background of IAP in the world and in Turkey. Following the introduction, accomplishments and successful outcomes of the program are discussed and the paper ends with discussions and future work.

\section{Brief history of industry-academia cooperation in the world}

In the countries with a history of technological development and innovation, the foundations of IAP have been laid down centuries ago. For example, The Royal Society of London was founded in England in the second half of the 17th century. In Europe, companies began to work together with university researchers in the 19th century. Among the very first official steps of university-industry cooperation in the world, there are the 1862 Morrill Land-Grant Acts drafted by the US Congress. In these acts, it was foreseen that the state would donate land to the schools and institutions in order for them to give practical courses to agriculture and industrial corporations related to their fields and to implement these courses in addition to classical training [2].

Following the second industrial revolution, industry-academia cooperation began to further emerge in the United States, Harvard and MIT leading the efforts. Also, Industry/University Cooperative Research Centers program was founded and run by the National Science Foundation. In this program, Yale University and Gilead Sciences have collaborated on cancer research, aiming to develop and clinically validate novel cancer therapies [3]. In this agreement, the company is granted the first option to license Yale inventions, which are results of the collaboration.

In 1994, Motorola and Arizona State University signed an agreement. According to the agreement, Motorola assigned its full-time employees to the Arizona State University Research Center [4]. Also, Texas Instruments Incorporated (TI) has been a long-standing partner of Georgia Institute of Technology's School of Electrical and Computer Engineering, where TI provided a $\$ 2.2$ Million grant to form a graduate program on analog integrated circuit design [5].

In 2007, JP Morgan Chase announced that they had signed an IAP agreement with Syracuse University by investing $\$ 30$ Million in the university to find a training program in financial services technology and infrastructure for the benefit of the region [6]. IBM and ETH Zurich University also have a long collaboration history; University of Zurich providing human resources training required by technology roadmap of IBM. In the laboratory which was founded with the support of IBM, both IBM and the University of Zurich had continued their research activities [7].

Developed in partnership with Worchester Polytechnic Institute and BAE Systems, three graduate programs aiming to train the talent and workforce to meet the needs of the company 
were opened [8]. Likewise, San Jose University's collaboration with KLA-Tencor for the graduate program in optoelectronics [9] and the National Institute of Aerospace's

collaboration with multiple universities in graduate programs [10] are other examples of IAP.

As China's changing role as a "world's manufacturer" to the "technology developer" in the global market, collaborations with international universities have been established to make the companies in China more productive and to improve their ability to compete internationally. Especially co-operation of East Asian countries such as Taiwan, Singapore and Korea, which have industrialized economies with the universities in Russia, Brazil, India and Australia contributed greatly to provide innovation [11].

\section{Brief history of industry-academia cooperation in Turkey}

In Turkey, there have recently been several company-university cooperation examples with various mechanisms and methods. For example, Vestel Inc. and Özyeğin University collaborated for Vestel Technology Academy in 2010, offering graduate degrees with a specialized industry graduate program [12].

Air Transport Management Master Program was initiated in 2013 with the cooperation between Istanbul Technical University (ITU), Turkish Airlines (THY) and Boeing in order to train employees for commercial aviation tasks [13].

In 2014, Bahçesehir University (BAU)-Netaş Techno Academy was launched with the collaboration between Bahçesehir University and Netaş Inc., which is specialized in telecommunications [14]. Also, programs focused on computer engineering, multimedia technologies and cybersecurity were initiated. Additionally, defense industry oriented graduate programs were initiated in universities. "Defense Electronics and Defense Platforms Master's Program" were founded at Başkent University [15] and "Defense Technologies" program was opened at ITU in order to train engineers to meet the needs of the defense industry [16].

As it can be seen from the brief history and listed examples, there are several different approaches to IAP. Academic and industrial graduate programs are one of the main methods to utilize such cooperation, which are formed and shaped by taking technological and academic needs of the companies into consideration. To meet the needs of Aselsan Inc., defense industry and the country, Aselsan Academy, which is a new model that can meet the needs of industry and more than one university was developed and launched.

\section{Aselsan Academy Program}

Aselsan, based in Ankara, is the largest defense technologies company in Turkey, in terms of sales and net worth; holding the 55th place in world's top 100 defense companies in 2018 [17]. The company has expertise in design, manufacturing and integration of land, naval and aerial defense and weapon systems, radars; electro-optics, communication, space, medical, energy, security equipment with sales to both domestic and international market. Aselsan spans across five main divisions with more than six thousand employees. Four thousand employees hold engineering B.S. degrees, more than a thousand have M.Sc. degrees and more than three hundred are Ph.D. holders. The company, since its foundation in 1975, has always been in close relation with academia, is eager to employ people with graduate degrees and 
additionally encourages employees to pursue their graduate degrees during their employment in Aselsan. Not only the previously obtained graduate degrees are counted as points just like work experience upon employment, but also the degrees obtained during the employment period are awarded points in addition to yearly performance points, which are required for promotions. Both engineering and administrative personnel are encouraged to obtain graduate degrees from highly ranked universities, by allowing them to pursue their degrees during regular work hours without any wage reduction or necessity to work extra hour to cover up for the academic hours they used.

Aselsan Academy was founded in June 2017 [18] as an official company directorate to regulate and manage engineering graduate studies of the Aselsan employees towards needs and benefits of the company. Employees can obtain their Master of Science and Doctor of Philosophy degrees upon completion of the specific program requirements. Aselsan Academy expects from students that, their graduate studies to match with their projects in Aselsan with respect to main campus university regulations. Employees are required to carry out their job responsibilities and graduate studies at the same time.

\section{Organization}

Aselsan Academy is officially recognized and formed by the agreement between Aselsan, Higher Education Council (YÖK) of Turkey and four major state research universities. In alphabetical order, Gazi University (GU-Ankara), Gebze Technical University (GTUKocaeli), Istanbul Technical University (ITU-Istanbul) and Middle East Technical University (METU-Ankara) are involved in the agreement. The organization is illustrated in Figure 1. The departments are chosen considering the needs of Aselsan: electric and electronic, mechanical, computer and materials engineering. Diplomas are awarded by the universities and are exactly the same as the diplomas awarded by the universities to their own students with all liabilities and benefits. There are no necessity for additional marking or mention to Aselsan Academy on diplomas, but transcripts can contain industry and technology courses given by Aselsan.

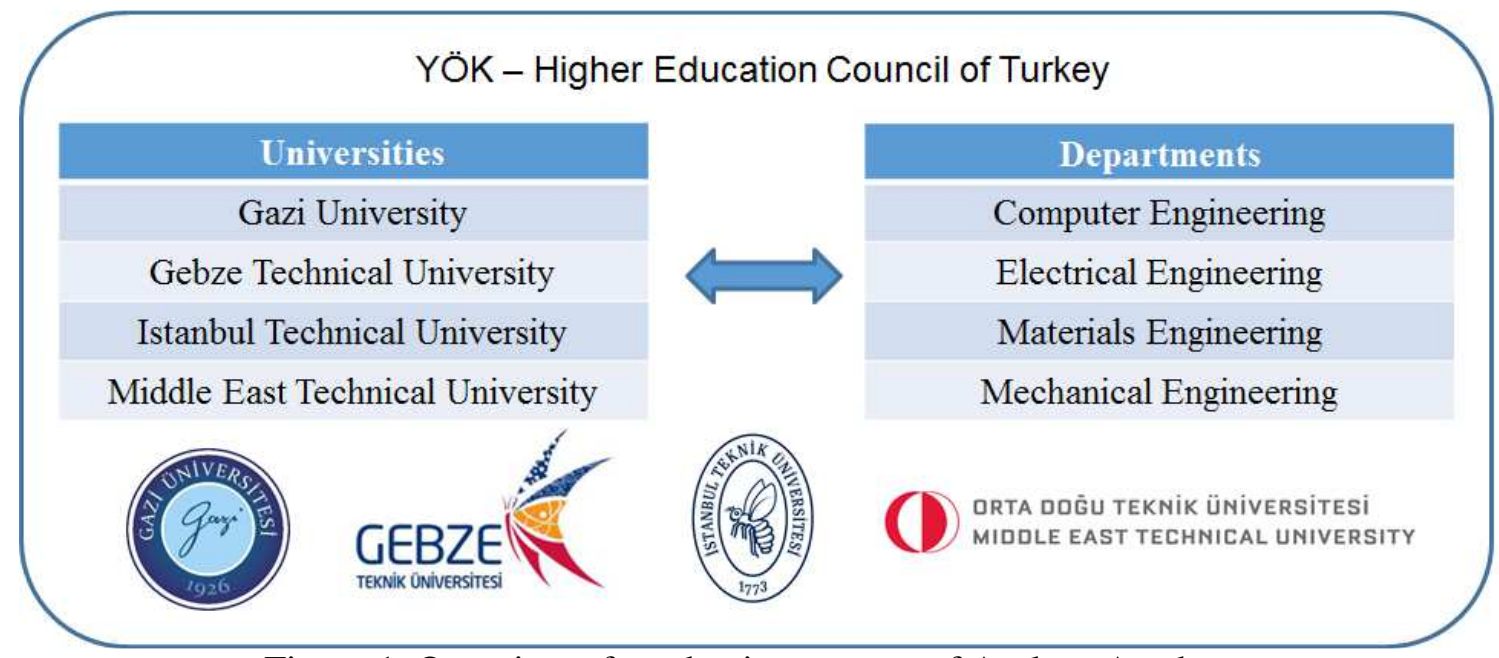

Figure 1. Overview of academic structure of Aselsan Academy

Inside Aselsan organization, Aselsan Academy is a directorate operating under Technology and Strategy Management Division. Operations are managed by the Aselsan Academy Council; consisting of four Aselsan employees (including chairperson) and representatives 
from the participant four universities (usually vice-rector, rector consultant or graduate school dean). Programs are reviewed by Aselsan Academy Council monthly and by Higher Education Council (YÖK) of Turkey annually. Operations are run by Academy directorate, consisting of three managerial units: Academic Relations, Student Affairs and Academic Services departments with a total number of 14 full time employees as of February 2019. Academic discipline and probation of students are handled by the universities, to which the student is enrolled to, according to the university rules. Additionally, Aselsan employees are also responsible to comply with the company rules, any violations are investigated by Aselsan Disciplinary Council.

\section{Students and admission}

Aselsan Academy program is only available to full-time employees of Aselsan, who would like to obtain their graduate degrees from aforementioned engineering disciplines. Aselsan Academy body acts as an out-of-campus agent of the partner universities for admission and all types of administrative processes. Subcontractor employees or outside parties are not allowed to enroll to Aselsan Academy. Employees with B.S. degree may apply for the Master of Science program and M.Sc. degree holders can apply for the Ph.D. program, i.e. currently no combined M.Sc./Ph.D. option is available.

Current number of students and their distribution with respect to programs, universities, departments and academic years are shown in Table 1. Almost 6\% of the Aselsan employees are enrolled in Aselsan Academy program. As seen from the table, the majority ( 59\%) of the students are enrolled to Istanbul Technical University. Also, electrical engineering students constitute more than half $(\sim 58 \%)$ of the total number of students enrolled. Highest enrollment numbers are seen at; 17/18 Spring after the first successful semester of Aselsan Academy and at $18 / 19$ Fall semester as a result of typical high graduation rates at spring semesters in Turkey.

Table 1. Student number with respect to program, university, department and years.

\begin{tabular}{|l|c|c|c|c|c|c|c|c|c|c|c|c|c|c|c|c|}
\hline & \multicolumn{3}{|c|}{$17 / 18$ Fall } & \multicolumn{4}{|c|}{$17 / 18$ Spring } & \multicolumn{4}{c|}{$18 / 19$ Fall } & \multicolumn{4}{|c|}{$18 / 19$ Spring } & Total \\
\hline & GU & GTU & ITU & GU & GTU & ITU & METU & GU & GTU & ITU & METU & GU & GTU & ITU & METU & \\
\hline Comp. Eng. & 3 & 3 & 9 & 2 & 8 & 6 & 1 & & 3 & 13 & 3 & 2 & 3 & 11 & 2 & 69 \\
\hline Elec. Eng. & 12 & 4 & 30 & 7 & 10 & 35 & 9 & 17 & 6 & 42 & 10 & 13 & & 15 & 2 & 212 \\
\hline Mech. Eng. & 6 & & 10 & 8 & & 12 & & & & 13 & 3 & 3 & & 12 & 3 & 70 \\
\hline Mat. Eng & & & & & 2 & 1 & & & 1 & & 1 & & 2 & & 1 & 8 \\
\hline Total & 21 & 7 & 49 & 17 & 20 & 54 & 10 & 17 & 10 & 68 & 17 & 18 & 5 & 38 & 8 & 359 \\
\hline
\end{tabular}

Eligibility criteria are set by each department and university; very similar to universities' own requirements. The main requirement for students to be admitted to Aselsan Academy is that; the field in which the degree pursued and the graduate research study topic should match with the working unit and the topics/projects of the employee. Admissions are initially collected and sorted by Aselsan Academy, and then sent to universities for evaluation and official acceptance. Before the university admission process, the applications are reviewed by the Academy Council with main criteria applied being suitability of the thesis topic. Feedback is given to her/him to change their thesis topics, if the topic is found inappropriate. Students are allowed to pick any university upon their request or a university can be specified by the directorate according to the content of the thesis work and also in accordance with the expertise of the academic staff of the departments. Depending on the demand of the 
departments, applicant employees may be interviewed by committees formed by the departments in Aselsan's main campus before admission.

\section{Courses}

As stated in the official agreement, all courses take place at the main campus of Aselsan. Professors from ITU and GTU travel to Ankara once or twice a week to give their lectures. All travel and accommodation are met by Aselsan. There are currently 13 classrooms used for courses. Professors from universities are paid on a per-hour basis at the end of each month according to lecture hours.

In terms of coursework requirements, only difference between Aselsan Academy students and universities' own students studied in the same program is due to the courses offered by Aselsan personnel with doctorate degree. The courses, which are pre-approved by university senates, have a unique "AAR" code. The courses are regarded and counted as university's own courses and each student can take a maximum number of two AAR courses. There are also some minor modifications in terms of must/elective courses throughout universities and programs. The departments also offer technical preparation pre-program courses to students, whose requirements are decided by the departments themselves. For example, there are many industrial engineering B.S. majors, who are enrolled to computer engineering programs. Undergraduate level courses such as "Operating Systems", "Software Engineering" and "Algorithms" are offered to such students.

The students who fail to complete degree requirements after they complete the coursework requirements, or leave the company, are legally committed to pay back 1.5 month equivalent per semester of their latest salary back to the company as compensation.

\section{Thesis/dissertation work}

The content of the thesis/dissertation study and their outcomes are the main IAP idea behind the foundation and operations of Aselsan Academy. In Aselsan Academy, it is ensured that graduate studies of the employees are directed towards the needs and aims of the company. Before Aselsan Academy is formed, employees were able to obtain permission for graduate studies regardless of the graduate program they are applying for or the thesis/dissertation topic. Currently, majority of the thesis/dissertation topics can be categorized as: $i$ ) design optimization topics, $i$ ) topics including new methods for existing process, products, and technologies, iii) new technologies and novel products.

In Aselsan Academy, the students should specify their thesis topics at the beginning of the program during admission. They are required to apply with a draft thesis/dissertation topic that should well match with their own responsibilities in their jobs and related to a technology, process or product of the unit they are working in. Students initially decide on the draft topic through discussions with their managers, experienced coworkers, and doctorate holding employees (possibly co-supervisors, discussed in next part). The topics are further shaped through interviews conducted by the personnel of the Student Affairs and Academic Relations units of the Aselsan Academy, and their co-supervisors. Also, a candidate for principal thesis supervisor (from universities) should be specified during the interview. Thesis topic offer and candidate(s) for supervisor information are then sent to the universities and departments along with required documents and graduate exam and foreign language test scores. Evaluations for general admission requirements and suitability of the thesis topic and 
the supervisor are done by the departments and universities, and the universities admit students with their thesis titles and their supervisors at the beginning of the program.

\section{Supervisors and co-supervisors}

Principal thesis/dissertation supervisors are obliged to be universities' full time faculty members. Depending upon needs and expertise, supervisors should be from the same department (of the same university to which the student is enrolled to). The responsibilities of the supervisors are not different than supervising responsibilities at their own universities.

In addition to the supervisor, as stated with the agreement signed with Higher Education Council (YÖK) of Turkey, a doctorate holder Aselsan employee co-supervisor should be specified during admission. Co-supervisors act as an in-company mentor for the student, helping them with the graduate studies and ensuring the research serves to the company benefit.

Supervisors also receive hourly payments for thesis/dissertation meetings that they held with students, similar to the faculty. They are encouraged to have research meetings with students at Aselsan, preferably at the students' own labs, test sites and offices in order for them to touch to the project and the company.

\section{Accomplishments}

\section{Thesis topics}

Aselsan Academy program has the potential to be very effective in directing employees' graduate studies towards the needs and aims of the company. Almost all of the graduate thesis/dissertation work of the employees are directed towards the projects in their managerial unit. The aim of Aselsan Academy Program is to make employees in the program take the courses fitted into the projects they take part. In this way, the employee will improve his working skills as target-oriented. On the other hand, Aselsan will raise experts in their working areas and use the outcomes of the thesis in its projects as innovative solutions. So, Aselsan Academy provides employees with the opportunity to study on the thesis topics, which are related to their current projects and self-financed $R \& D$ projects.

\section{Academia and industry involvement}

Nearly all of the academicians involved in the Aselsan Academy program as supervisors and/or lecturers express their willingness for being part in the coming semesters. Thanks to this program, they have chance to see company assembly, special laboratories and design plants, as well as to learn about important military projects.

Defense industry is one of the most important industrial and economical focus areas for the country, especially during the last 15 years with a significant amount of investment made in product development and R\&D to develop national defense systems and new technologies. However, it can be argued that the IAP has not spread fast enough, compared to the pace of the increase in national defense R\&D activities. Aselsan Academy acts as a tool not only to close the gap between academia and defense industry, but also to realize a model for other industries and universities in Turkey to pursue a similar path. 


\section{Student interest and convenience}

Students/employees are willing to join the program, as it gives them the opportunity to fulfill their daily task responsibilities and complete their graduate studies during the same working hours. With this opportunity offered by Aselsan Academy, students can work more efficiently on their graduate studies and daily job tasks, on a common industrial field.

\section{Future work and insight}

As Aselsan Academy heads towards its 4th semester, with more than three hundred students; completion of first M.Sc. degrees are expected in summer 2019. Aselsan's expected outcomes from the program are innovative and improved products and novel technologies, which would improve the sales, revenues and product range. Similarly, expected academic outcomes of the program from the academic side are, conference proceedings, research papers, patens and intellectual property rights.

Aselsan Academy has set a role model for other sectors. Other similar institutions and universities are suggested to adopt this model and expand IAP throughout the country.

Another important issue regarding Aselsan Academy is the intellectual property rights. In the official agreement between Aselsan and the universities, it is stated that the intellectual property rights of all the research and outcomes of the graduate studies belong to Aselsan.

\section{Acknowledgement}

Presidency of Higher Education Council , the rectors of the collaborating universities,. The efforts of governmental institutions and their employees, collaborating universities and their staff and Dr. Onursal Önen put the manuscript, Aselsan executives and employees that helped for realization of Aselsan Academy program are all kindly acknowledged.

\section{References}

[1] S. Chai, W. Shih, "Bridging science and technology through academy-industry partnerships", Research Policy, vol.45, issue: 1, pp. 148-158, 2016.

[2] S. Key, "Economics or Education: The Establishment of American Land-Grant Universities", The Journal of Higher Education, vol.67, issue: 2, 1996.

[3] Yale University, "Collaborating with Industry", [Online]. Available: http://ocr.yale.edu/faculty/collaborating-industry", [Accessed 21 Jan 2019].

[4] E. L. Hall, "Motorola/Arizona State University-an experiment towards industrial/academic excellence", in Proc. of the $11^{\text {th }}$ Biennial University/Government/Industry Microelectronics Symposium, 16-17 May 1995, pp. 41-44.

[5] Georgia Institute of Technology, “Texas Instruments Enhances Tech's Analog Engineering Program”, [Online]. Available: http://rincon-mora.gatech.edu/misc/gatechti.htm, [Accessed 21 Jan 2019].

[6] CSR News, "JPMorgan Chase and Syracuse University Partner to Create Innovative Financial Services Technology and Infrastructure Programs", 2007. [Online]. Available: http://www. csrwire.com/press_releases/16173-JPMorgan-Chase-and-Syracuse-UniversityPartner-to-Create-Innovative-Financial-Services-Technology-and-Infrastructure-Programs, [Accessed 21 Jan 2019]. 
[7] IBM Zurich, “IBM and ETH Zurich form \$90 Million Partnership in Nanoscience”, 2008. [Online]. Available: https://www.zurich.ibm.com/news/08/nanotech.html, [Accessed 21 Jan 2019].

[8] BAE Systems, "Computer Science Certificate", [Online]. Available:

http://wp.wpi.edu/bae/, [Accessed 21 Jan 2019].

[9] San Jose State University, "KLA Tencor - MS Engineering, Specializatin in

Optoelectronics Systems", [Online]. Available: https://ges.sjsu.edu/programs/corporatedegree/general-engineering/kla-tencor-ms-engineering-specialization, [Accessed 21 Jan 2019].

[10] National Institute of Aerospace, "M.S. and Ph.D. Programs", [Online]. Available: http://www.nianet.org/education/graduate-education/degree-programs/, [Accessed 21 Jan 2019].

[11] Q. Yuanjian, D. Mkhitaryan, "University-Industry Partnership in New Energy Vehicle Industry in China", International Journal of Innovation and Academic Development, vol.2, issue: 6

pp. 49-58, 2017

[12] Vestel Inc., "Vestel'de Eğitim Hayatın Bir Parçası"," [Online]. Available:

http://www.vestelkariyer.com/vestelde-kariyer/vestel-teknoloji-akademisi-nedir, [Accessed 21 Jan 2019].

[13] Turkish Airlines, “Air Transport Management Master Program”, [Online]. Available: https://akademi.thy.com/ozelprogramdetay/air-transport-management-master-program/1, [Accessed 21 Jan 2019].

[14] Netaş Inc.,"Netaş ve Bahçeşehir Üniversitesi'nden “Bilgisayar Mühendisliği Tezli Yüksek Lisans ve Doktora Programı”, [Online]. Available:

http://www.netas.com.tr/medya/netas-bau-techno-academy/, [Accessed 21 Jan 2019]. [15] Başkent University, "Defense Electronics Defense Platforms Master's Program", [Online]. Available:

https://angora.baskent.edu.tr/bilgipaketi/?dil=TR\&menu=akademik\&inner=genelBilgi\& birim $=5034$, [Accessed 21 Jan 2019].

[16] Istanbul Technical University, "Savunma Teknolojileri”, [Online]. Available: http://petek.fbe.itu.edu.tr/programmes.aspx?i=273, [Accessed 21 Jan 2019].

[17] Defense News, “Top 100-2018”, 2018, [Online]. Available: http://people.defensenew.com/top-100/, [Accessed 21 Jan 2019].

[18] Defence Turkey, "The Launch Ceremony Aselsan Academy and Universities Postgraduate Training Program Protocol was Held in Ankara”, 2018, [Online]. Available: http://www.defenceturkey.com/en/content/the-launch-ceremony-of-aselsan-academy-anduniversities-postgraduate-training-program-protocol-was-held-in-ankara-

3057\#.XHT4Rogzbcs, [Accessed 21 Jan 2019]. 